\title{
Relationship between the indices of physical and mechanical properties of coal and rock, gas saturation and tectonic dislocation of Donbas
}

\author{
Dmytro Pymonenko ${ }^{1, *}$ \\ ${ }^{1}$ Institute of Geotechnical Mechanics named by N. Poljakov of National Academy of Sciences of \\ Ukraine, 49005, Dnipro, Simferopolska Str., 2a, Ukraine
}

\begin{abstract}
The article deals with the distribution of disturbances in the coal-bearing deposits of Donbas and establishment of the relationship between the indices of physical and mechanical properties of coal and rock, gas saturation and tectonic dislocation. To solve the problems, statistical methods were used (correlation and regression analysis). The schemes of deformations of Donbas have been built, both in individual indices and in indices of complex dislocation, which reflect the regional patterns of distribution of the deformations of various types throughout the Donetsk basin. Close statistical relationship has been established between indices of tectonic dislocation, gas saturation, physical and mechanical properties of coal and rocks, which allows the use of the indices of tectonic dislocation to predict gas content at the regional level.
\end{abstract}

\section{Introduction}

It is known that the gas content of coal seams and rocks enclosing the seam varies widely, depending on the geological and tectonic structure and age of the deposit, the extent of coal saturation, the degree of catagenesis of rocks and coal, reservoir properties, their dislocation and other factors. Tectonic dislocation is one of the main factors affecting the gas content of the massif and the gas content of the mine workings, as well as the efficiency and safety of the mining operations. It complicates the technical conditions of coal mining, increases its cost, affects the hydrogeological regime, the redistribution of gases in the massif, the gas-dynamic activity of rocks. Intensification of coal mining, deepening of mining, creation of a new industry for extraction and utilization of methane from coal deposits has led to the need to summarize and analyze existing data on the tectonic characteristics of the geological objects under consideration to substantiate the approach to their possible prediction [1-5].

In this regard, the aim of the work is to study the patterns of distribution of disturbances in the coal-bearing deposits of Donbas and to establish the relationship between the indices of physical and mechanical properties of coal and rock, gas saturation and tectonic dislocation.

*Corresponding author: kvalitet@i.ua 


\section{Methods}

To characterize the tectonic dislocation, the actual material that reliably characterizes the dislocations of various types and sizes is currently accumulated. The modern structure of the basin is a result of the impact of geodynamic processes on the coal-bearing strata, as a result of which it has undergone corresponding deformations, the magnitudes of which can be judged by the angles of incidence of the rocks, the parameters of folded and rupture dislocations. It is proposed to use indices characterizing the intensity of rupture disturbance $K_{r}$, folded disturbance of $K_{f}$, variability of coal seams dip angles $K_{a}$, general deformation $K_{d}$ of coal-bearing strata [6].

The calculations of the tectonic dislocation of the basin were carried out on the basis [7]. Taking into account the scale of the research object, the parameters of folded and discontinuous structures (length of folds $1-10 \mathrm{~km}$ and amplitude $0.1-2 \mathrm{~km}$; length of breaks $1-10 \mathrm{~km}$ and amplitude $0.1-1 \mathrm{~km})$, squares $(20 \times 20 \mathrm{~km})$ were accepted. The basin area was divided into squares, within which the indices were calculated.

The index of variability of the angles of incidence of rocks in the area $\left(K_{a}\right)$ is calculated by the formula:

$$
K_{a}=\left(\alpha_{\max }^{\circ}+\alpha_{\min }^{\circ}\right) / 180
$$

where $\alpha_{\max }^{\circ}$ and $\alpha_{\min }^{\circ}$ are respectively the maximum and minimum angles of incidence of rocks in the area under study.

The index of rupture disturbance is calculated by the formula:

$$
K_{r}=\sum_{i=1}^{n} L_{i} / \sum_{i=1}^{n} L_{\max }
$$

where $L_{i}$ - length of the sum of the lengths of faults measured within a single square, $\mathrm{km} ; L_{\max }-$ the maximum length of the amount of faults within the region or zone, $\mathrm{km}$.

The index of folded disturbance is calculated by the formula:

$$
K_{f}=K_{f}^{i} / K_{f}^{\max },
$$

where $K_{f}^{i}$ - folded disturbance within the investigated area, $\mathrm{km} ; K_{f}^{\max }$ - the maximum value of the index of folded disturbance within the region or zone, $\mathrm{km}$.

Its value is calculated by the formula:

$$
K_{f}^{\max }=\sum_{i=1}^{n}\left[\left(l_{i}-l_{0}\right) / l_{0}\right]
$$

where $l_{i}$ - length of the $i$-isogypsum within the structure, $\mathrm{km} ; l_{0}$ - distance between the ends of the $i$-isohypsum within the structure, $\mathrm{km} ; n$ - number of structures within the study area.

Total dislocation index $K_{d}$ :

$$
K_{d}=\sqrt{K_{a} \cdot\left(K_{r}+K_{f}\right)}
$$

All indices are non-dimensional and vary in the range from 0 to 1 . Such approach allows to compare different sections (mines, layers), both by types of dislocations, and by their number. 
The proposed indices allowed to construct schemes of deformations Donbas, both in individual indices and in terms of complex dislocation, reflecting regional patterns of distribution of the deformations of various types throughout the Donetsk basin.

The process of complete deformation [8], first, consists of three stages, each of which involves a certain state of the massif: elastic, viscous (plastic), brittle; secondly, with the growth of the magnitude of stresses, the sequential formation of dislocations occurs: from plastic (folding) to brittle (rupture), from microdislocations to large amplitude disturbances. Rupture low-amplitude disturbances are formed at the fragile stage of complete deformation.

On this basis, the scheme of folded disturbances reflects the intensity of plastic deformations, rupture (mostly) - "brittle". The areas characterized by large angles of bedding of rocks $\left(50-80^{\circ}\right)$ are confined to the zones of deep faults of the Donbas, under the action of which they were formed. Consequently, the constructed schemes approximately reflect the intensity and heterogeneity of the stress-strain state of the massif at various stages of Donbas formation, allow by the geological data to identify areas with different types of dislocations.

A study of the physicomechanical properties and gas content of the Donbas rocks and coals in selected areas was carried out on the basis of a comparison of indices characterizing these factors. To characterize the physical properties of sandstone formations, the results of geophysical studies were used: longitudinal wave velocity $v_{\mathrm{p}}$ and electrical resistivity $\rho_{k}(\Omega \cdot \mathrm{m})$. Disturbance of coal seams was estimated by data of the breaking characteristics of coal seams $R c$. Assessment of the gas saturation of the massif was carried out according to the natural gas content of coal seams $G$ and the methanebearing capacity of mine workings $M$.

All the collected data were averaged by wells, by mine fields, exploration sites and in the whole Donbas regions. The collected data were calculated coefficients of pair correlation (Table 1).

Table 1. Pair correlation coefficients.

\begin{tabular}{|c|c|c|c|c|c|c|}
\hline Indices & $K_{d}$ & $R c$ & $\begin{array}{c}v_{\mathrm{p}}, \\
\mathrm{km} / \mathrm{s}\end{array}$ & $\begin{array}{c}\rho_{\mathrm{k}}, \\
\Omega \cdot \mathrm{m}\end{array}$ & $\begin{array}{c}M, \\
\mathrm{~m}^{3} / \mathrm{t}\end{array}$ & $\begin{array}{c}G, \\
\mathrm{~m}^{3} / \mathrm{t}\end{array}$ \\
\hline$K_{d}$ & 1.00 & 0.59 & 0.82 & 0.73 & 0.77 & 0.88 \\
\hline$R$ & 0.59 & 1.00 & 0.85 & 0.85 & 0.80 & 0.84 \\
\hline $\mathrm{v}_{\mathrm{p}}$ & 0.82 & 0.85 & 1.00 & 0.97 & 0.94 & 0.72 \\
\hline$\rho_{\mathrm{k}}$ & 0.73 & 0.85 & 0.97 & 1.00 & 0.89 & 0.67 \\
\hline$M$ & 0.77 & 0.80 & 0.94 & 0.89 & 1.00 & 0.92 \\
\hline$G$ & 0.88 & 0.84 & 0.72 & 0.67 & 0.85 & 1.00 \\
\hline
\end{tabular}

Analysis of the correlation coefficients showed that the overall index of the dislocation of $K_{d}$ is closely related to the physico-mechanical properties $\left(R c, v_{\mathrm{p}}, \rho_{\mathrm{k}}\right)$ and indices characterizing the gas content in the rock mass $(G, M)$. The indices characterizing the gas content of the massif are closely related to the physico-mechanical parameters, which, on the one hand, is consistent with many years of research of these parameters in the Donbas and corresponds to the very nature of transformation of rocks and coals in the regional plan, on the other hand, indicates the validity of the results.

To assess the relationship between gas content $G$ and methane-bearing capacity $M$ with indices of variability of the angles of incidence of rocks in the area $K_{a}$, rupture disturbance $K_{r}$, folded disturbance $K_{f}$, characterizing tectonic dislocation, we use the method of multiple linear regression, the general equation of which is written as: 


$$
y=b_{0}+b_{1} \cdot x_{1}+b_{2} \cdot x_{2}+\ldots+b_{k} \cdot x_{k},
$$

where $b_{i}-$ are regression parameters (coefficients); $x_{i}$ - regressors (model factors); $k$ - the number of factors of the model.

As a result of numerical calculations using the methods of mathematical statistics, taking into account the expression (6), the following regression equations were obtained, respectively, for the gas content of the massif $G$ and the methane-bearing capacity of the space developed $M$ :

$$
\begin{gathered}
G=5.0+12.2 \cdot K_{r}-7.1 \cdot K_{f}+14.3 \cdot K_{a} ; R=0.71 \\
M=7.2+11.8 \cdot K_{r}-14.7 \cdot K_{f}+35.7 \cdot K_{a} ; R=0.84
\end{gathered}
$$

Check of the significance of the coefficients of multiple correlation $R$ will be performed using Student's criterion $t$. The observed (actual) value of this criterion is determined by:

$$
t_{\text {actual }}=\sqrt{R^{2} \cdot(n-1) /\left(1-R^{2}\right)},
$$

The values for (7-8) calculated from this formula, equal to 2.5 and 3.8, respectively, are compared with the critical value of the $t$-test. According to the distribution table $t_{\text {table }}=2.4$ (significance level 0.05). Since, $t_{\text {actual }}>t_{\text {table }}$, then the obtained values $R$ are recognized as significant, which allows to conclude that there is a close statistical relationship between the variables under study. The adequacy test was performed by the Fisher criterion for a significance level of 0.05 and degrees of freedom $(3 ; 3)$. According to the distribution table, we get $F_{\text {table }}=9.28$. The calculated values of the Fisher criterion for equations $(7-8)$ are 0.57 and 2.46 , respectively. Since the given values are much smaller than the tabular ones, the linear regression models under study are adequate [9].

\section{Results and discussion}

As a result of calculations, regression equations were obtained (Table 2), describing the interrelation of physicomechanical properties $\left(v_{\mathrm{p}}, \rho_{\mathrm{k}}\right)$ and indices characterizing the gas content in the rock mass $(G, M)$ with the total dislocation factor of the $K_{d}$, and graphs were made (Fig. 1).

The obtained dependences are explained by the effect of dislocation on the gas-saturated medium. The relationship between the values of indices of the total dislocation of $K_{d}$ and the velocity of longitudinal waves $v_{\mathrm{p}}(1)$ is logically explained by the fact that when the dislocation increases the degree of catagenetic transformations increases, the porosity and permeability of rocks decrease, their density increases. The resulting dependence indicates the influence of external tectonic forces on rock compaction.

The dependencies between the values of the total dislocation factor of the $K_{d}$, the methane-bearing capacity of the workings $M(3)$ and the gas content of the coal seams $G$ (4) have a parabolic shape with a maximum of values at the level of $(0.4-0.5) K_{d}$. Obviously, an increase in dislocation to this value leads to an increase in fracturing (decompaction) of the massif and an improvement in the reservoir properties of rocks and coals, which increases its gas saturation, but a further increase in dislocation leads to significant disturbance and, as a result, to degassing the massif.

Thus, using the methods of mathematical statistics, the generalized dependencies between the indices of tectonic dislocation and gas saturation of the massif have been established. Consequently, the patterns of distribution of dislocation and gas content are similar and interrelated, which reflects the influence on the formation of these factors of 
uniform geodynamic processes and allows the use of indicators of tectonic dislocation to predict gas content at the regional level.
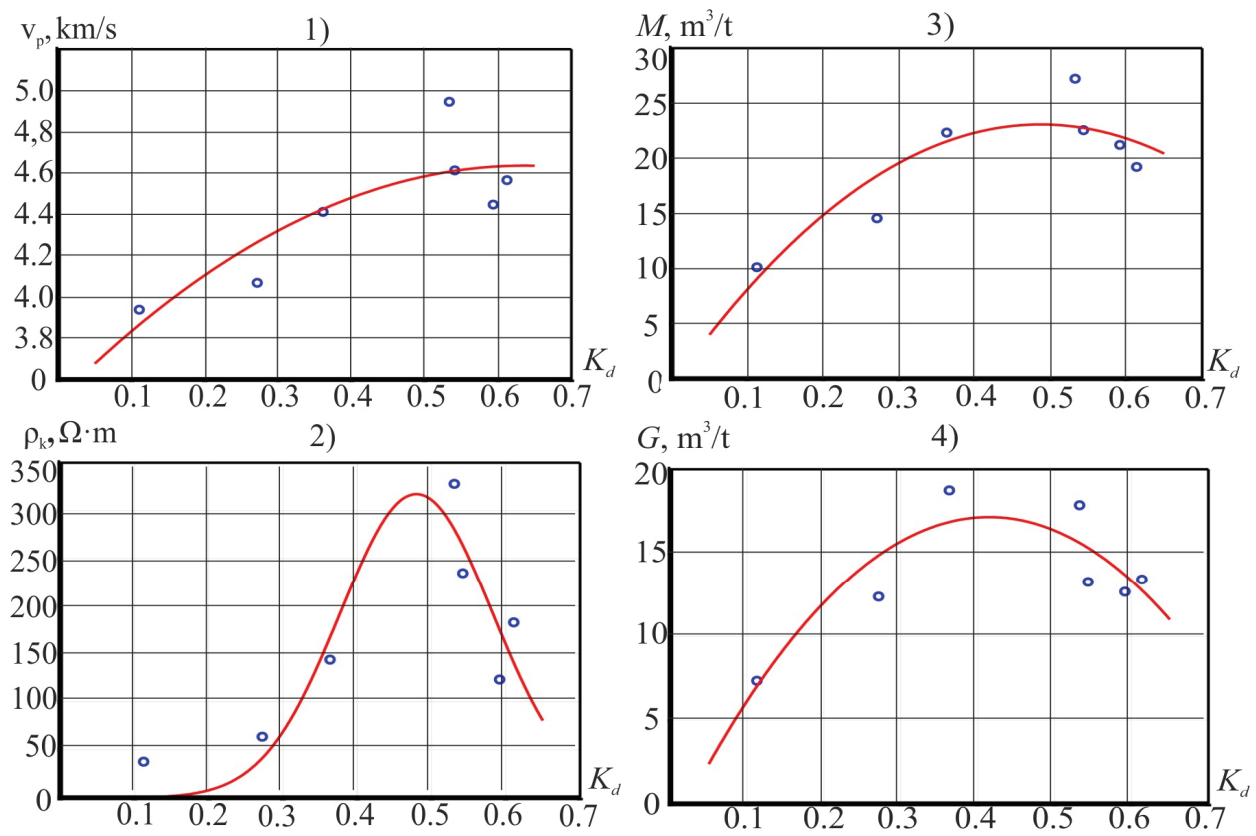

Fig. 1. The graphs of the relationship between the values of total dislocation coefficient $K_{d}$ and the velocity of longitudinal waves $v_{\mathrm{p}}$, electrical resistivity $\rho_{\mathrm{k}}$, methane-bearing capacity $M$, gas content of coal seams $G$.

Table 2. Regression equations and validation criteria.

\begin{tabular}{|c|c|c|c|c|}
\hline$\#$ & Regression equation & $\begin{array}{c}\text { Coefficient of } \\
\text { correlation } \\
\text { and } \\
\text { determination } \\
R \text { and } R^{2}\end{array}$ & $\begin{array}{c}\text { Criteria } \\
\text { Fisher }(F) \\
\text { and } \\
\text { Student }(t)\end{array}$ & $\begin{array}{c}\text { The confidence } \\
\text { intervals of the coeff. of } \\
\text { the equations } b_{0}, b_{1}, b_{2}\end{array}$ \\
\hline 1 & $v_{\mathrm{p}}=3.51+3.55 \cdot K_{d}-$ & $0.90 ; 0.81$ & $8.53 ; 2.92$ & $2.29<b_{0}<4.72$ \\
& $-2.79 \cdot K_{d}^{2}$ & & & $-4.04<b_{1}<11.14$ \\
& & & & $-12.85<b_{2}<7.26$ \\
\hline & $\rho_{\mathrm{k}}=e^{-5.13+45.39 \cdot K_{d}-47.31 \cdot K_{d}^{2}}$ & $0.91 ; 0.82$ & $9.11 ; 3.02$ & $-15.78<b_{0}<5.52$ \\
& & & & $0.91<b_{1}<91.69$ \\
& $M=-0.63+97.33 \cdot K_{d}-$ & $0.89 ; 0.79$ & $7.37 ; 2.72$ & $-18.24<b_{0}<16.99$ \\
& $-99.89 \cdot K_{d}^{2}$ & & & $-12.70<b_{1}<207.36$ \\
& & & & $-245.73<b_{2}<45.93$ \\
\hline $4=-1.96+92.15 \cdot K_{d}-$ & $0.90 ; 0.81$ & $8.53 ; 2.92$ & $-14.35<b_{0}<10.43$ \\
& $-111.11 \cdot K_{d}^{2}$ & & & $14.77<b_{1}<169.53$ \\
& & & & $-213.66<b_{2}<-8.56$ \\
\hline
\end{tabular}




\section{Conclusions}

Thus, as a result of the research found:

- relationships were established between indices of tectonic dislocation $\left(K_{r}, K_{f}, K_{a}\right.$ and $\left.K_{d}\right)$, its gas saturation $(M, G)$, and the physico-mechanical properties of rocks and coals $(R$, $\left.v_{\mathrm{p}}, \rho_{\mathrm{k}}\right)$, confirmed by calculated correlation coefficients $(0.60-0.97)$ that indicates the formation of these factors under the action of some processes and the possibility of using indices of tectonic dislocation for the prediction of gas content;

- relationships between indices of general dislocation and indices characterizing the gas content in the rock massif $(G, M)$ and the physico-mechanical properties of rocks $\left(v_{\mathrm{p}}, \rho_{\mathrm{k}}\right)$ have been established, with the electrical resistivity increasing exponentially with an increase in the general tectonic dislocation rate and velocity of longitudinal waves, methane-bearing capacity and gas content are characterized by a parabolic dependence with maxima of $(0.4-0.5) K_{d,}$.

\section{References}

1. Bulat, A.F., Mineev, S.P., Prusova, A.A. (2016). Generating methane adsorption under relaxation of molecular structure of coal. Journal of Mining Science, 52 (1), 70-79

2. Bulat, A.F., Skipochka, S.I., Palamarchuk, T.A. (2010). Metanogeneraciya v ugolnyh plastah. Dnipropetrovsk: Lira LTD

3. Bulat, A.F., Pimonenko, L.I., Pimonenko, D.N. (2014). Ocenka perspektivnosti obektov dlya dobychi metana uglegazovyh mestorozhdenij Donbassa. Uhol Ukrainy, 6, 41-47

4. Mineev, S.P., Prusova, A.A., Kornilov, M.G. (2007). Aktivaciya desorbcii metana $v$ ugolnyh plastah. Dnipropetrovsk: Veber

5. Mineev, S.P. (2009). Svojstva gazonasyshennogo uglya. Dnipropetrovsk: NGU

6. Lukinov, V.V., Pimonenko, L.I. (2008). Tektonika metanougolnyh mestorozhdenij Donbassa. Kyiv: Naukova dumka

7. Ocheretenko, I.A. (1980). Geologo-strukturnaya karta doverhnepermskih otlozheniy Doneckogo ugolnogo basseyna

8. Yaroshevskij, V. (1981). Tektonika razryvov i skladok. Moskva: Nedra

9. Vukolov, E.A. (2008). Osnovy statisticheskogo analiza. Moskva: Forum 